\title{
Pathogenesis of acanthamoebic keratitis: hypothesis based on a histological analysis of 30 cases
}

\author{
Alec Garner
}

\begin{abstract}
The results of a histopathological study of $\mathbf{3 0}$ cases of Acanthamoeba keratitis are construed as indicating a four stage pathogenetic sequence: (1) initial infection, involving breaching of the surface epithelium; (2) keratocyte depletion by the invading trophozoites; (3) inflammatory response mediated by neutrophil polymorphonuclear leucocytes; (4) stromal necrosis attributable to leucocytic activity.

(Br F Ophthalmol 1993; 77: 366-370)
\end{abstract}

Acanthamoebic keratitis is now sufficiently well known not to need an introduction. ${ }^{1}{ }^{2}$ Nevertheless, the numbers are small such that a comprehensive review in $1987^{1}$ was able to draw on reports of just 63 cases diagnosed in the United States. Given that $85 \%$ of cases are said to be linked to the wearing of contact lenses, ${ }^{3}$ even the 250 cases recorded by the Centers for Disease Control in Atlanta ${ }^{4}$ are trivial in comparison with the more than two million contact lens wearers in the United States. This suggests that the causative protozoon is either a weak pathogen or that

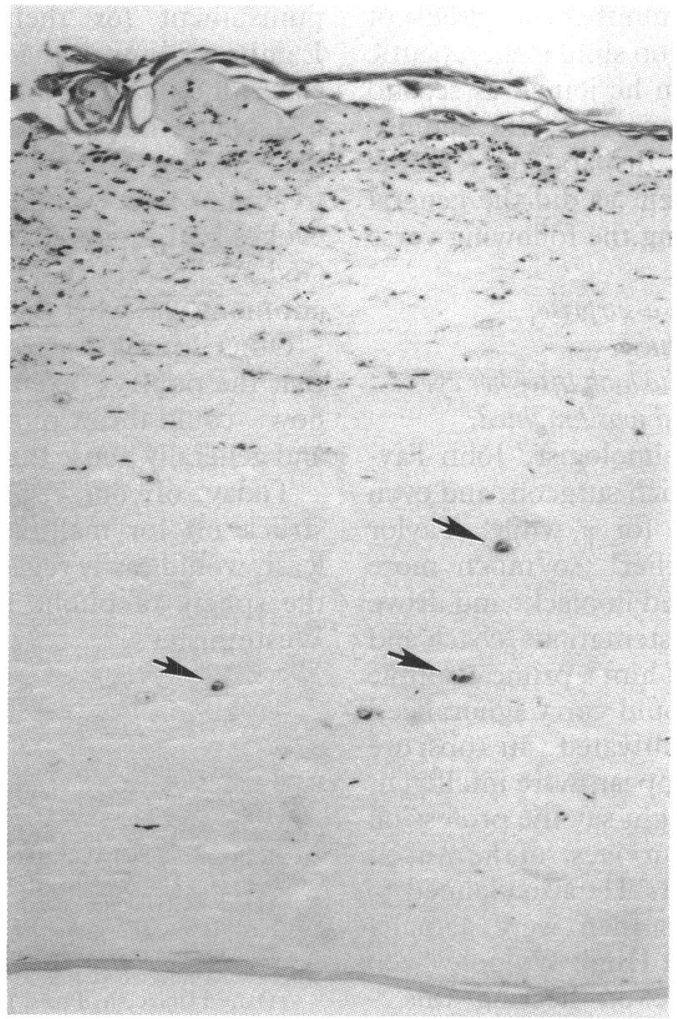

there is a high degree of innate host resistance. A relative lack of pathogenicity is emphasised by the widespread distribution of the various Acanthamoeba species and the corresponding potential for infection. Partly because of the small numbers available for study and partly because, until recently, ${ }^{5}$ it has proved difficult to develop a satisfactory animal model, understanding of the way in which Acanthamoeba damages the cornea is incomplete. In 1988 I presented a hypothesis based on the histological study of 10 personally observed cases ${ }^{6}$ and the purpose of the present paper is to reinforce the suggestions advanced on that occasion in the light of subsequent experience.

\section{Materials and methods}

Tissue suitable for analysis was available from 30 patients with histologically confirmed acanthamoebic keratitis (the 10 cases reported previously ${ }^{6}$ are included). Altogether, there were 22 full thickness corneal discs, two evisceration specimens including corneal tissue, five globes,

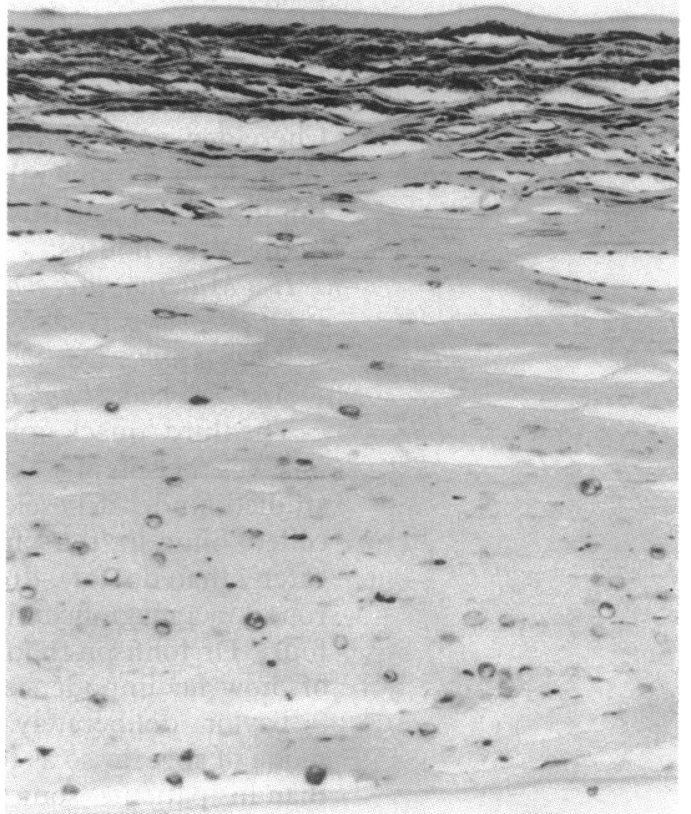

Figure 2 (Case 8). There is artefactual loss of surface epithelium in the presence of an intact Bowman's zone. Necrotic material is seen within the superficial stromal lamellae and numerous Acanthamoebae are present in the deeper stroma. There are almost no viable keratocyte nuclei (haematoxylin and eosin, $\times 205$ ). 
Figure 3 (Case 21). The anterior stroma is heavily infiltrated by

polymorphonuclear leucocytes, while Acanthamoebae (arrows) can be identified at all levels including the deeper lamellae where leucocytes are less evident. Epithelial loss is probably artefactual (haematoxylin and eosin. $\times 150$ ).

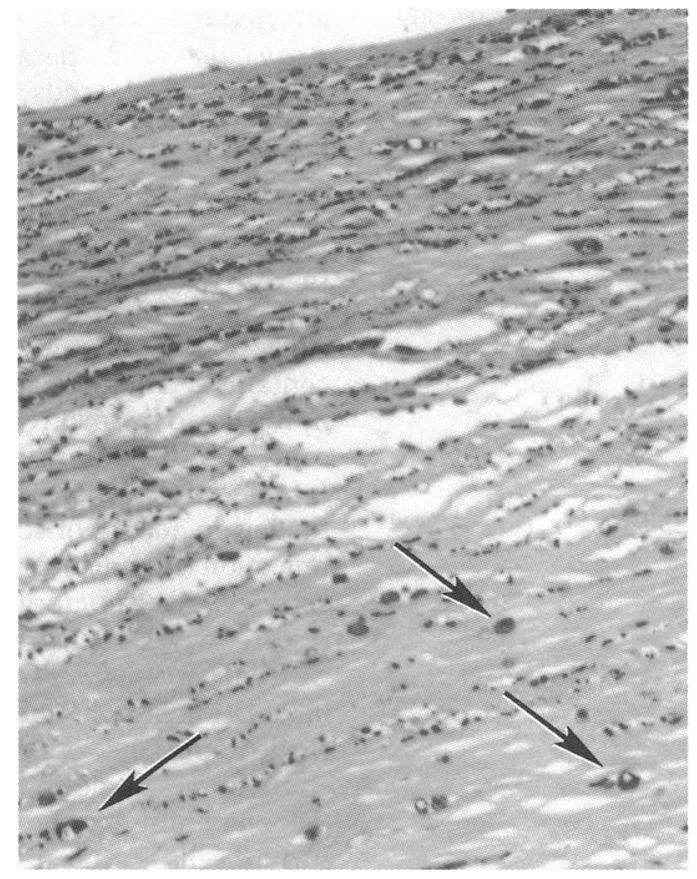

and one biopsy of the epithelium and anterior stroma. (In 11 cases repeated surgical procedures had resulted in the additional submission of failed graft material but evaluation was restricted to the initial host cornea in all but one instance (case 12).) Diagnosis was based primarily on the recognition of acanthamoebic trophozoites or cysts. Supplementary evidence in the form of in vitro culture, based on the inoculation of agar plates subsequently seeded with Escherichia coli bacilli and incubated for periods of up to 4 weeks, was available in 14 of the cases, while in 13 specific anti-Acanthamoeba antibody affinity was demonstrated using antiserum provided by courtesy of Dr D C Warhurst (London School of Tropical Medicine and Hygiene) and a standard indirect peroxidase antiperoxidase staining procedure.

Of the 21 cases in which the information was available, 16 were linked with contact lens wearing and in five there was a history of trauma involving the corneal surface. Fourteen patients had had a good response to an initial penetrating keratoplasty but 10 had subsequently incurred renewed inflammation in the donor tissue, while in the remaining six the outcome was unknown.

\section{Results}

Common to all 29 full thickness corneal discs was depletion of stromal keratocytes (Figs 1 and 2), particularly in the anterior half of the substantia propria. In two cases this was focally obscured by reparative fibrosis and in the single case in which anterior stroma only was available there was no apparent reduction. Loss of stromal collagen affecting variable areas of the corneas was also observed in the majority of specimens $(76.7 \%)$ and, while most obvious in the anterior lamellae, was associated with full thickness perforation in three cases. Leucocytic infiltration was also common but again was much more obvious anteriorly $(86.7 \%)$ than in the posterior stroma $(33 \cdot 3 \%)$, and consisted almost entirely of neutro- phil polymorphonuclear cells with scattered macrophages (Figs 3 and 4). Lymphocytes and plasma cells were rarely found. Absence of covering epithelium was another frequent finding but the extent to which this was artefactual could not always be determined.

In the five cases in which enucleation of the globe had been performed moderate to severe chronic uveitis was observed, most evident anteriorly and in the form of diffuse lymphocyte and plasma cell infiltration. Vascular congestion and chronic inflammation of the perilimbal bulbar conjunctiva was also evident.

All purely corneal specimens were examined for the presence of trophozoites or cysts at the resection margin but, in view of the sporadic distribution of the organisms, this was not considered to be a reliable exercise and the results are not recorded. Acanthamoeba was not detected in the sclera of the five enucleation specimens.

The findings in individual cases are listed in Tables 1 and 2 and summarised in Table 3.

\section{Discussion}

The low incidence of acanthamoebic keratitis despite the widespread prevalence of the causative organism is capable of at least two mutually compatible explanations. One is that the Acanthamoeba organism is a weak pathogen and the other is that the corneal epithelium presents a generally insurmountable barrier to invasion. Evidence bearing on the first of these possibilities is sparse and entirely circumstantial. Several epidemiological studies have detected evidence of an immunological response in clinically un-

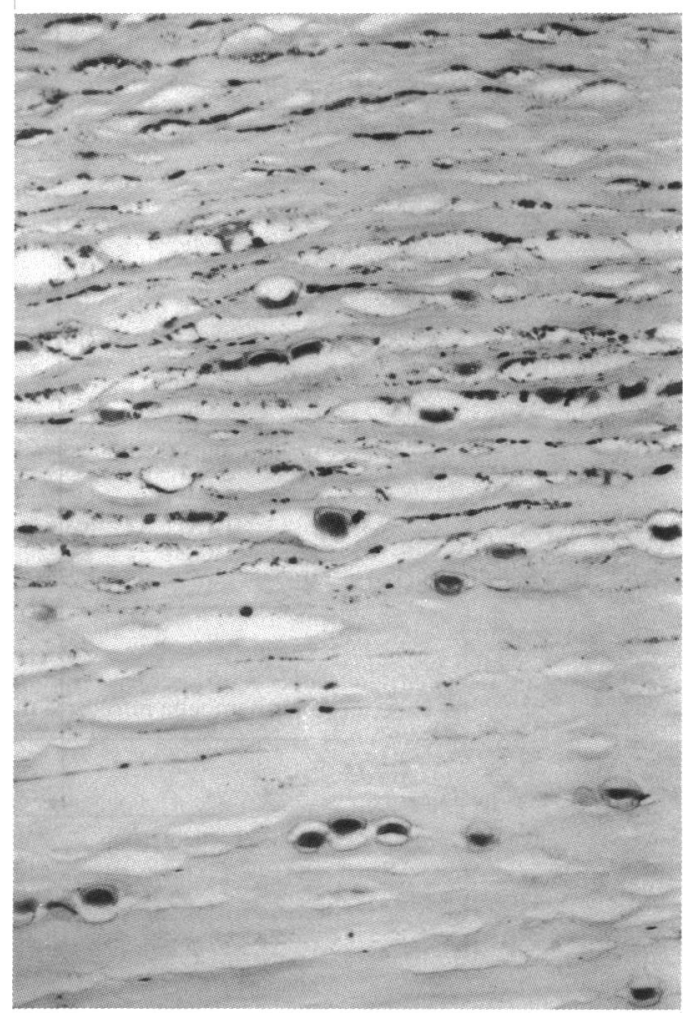

Figure 4 (Case 4). Polymorphonuclear leucocytic infiltration of the cormeal stroma is evident anteriorly. Acanthamoebae, seen mostly as encysted forms, are present at all levels but are most numerous posteriorly where leucocytes are few (haematoxylin and eosin, $\times 295$ ). 
Table 1 Histopathological and related findings in individual patients with acanthamoebic keratitis

\begin{tabular}{|c|c|c|c|c|c|c|c|c|c|}
\hline \multirow[b]{3}{*}{ Patient } & \multirow{3}{*}{$\begin{array}{l}\text { Epithelial } \\
\text { cell loss }\end{array}$} & \multicolumn{4}{|c|}{ Anterior stroma } & \multicolumn{4}{|c|}{ Posterior stroma } \\
\hline & & \multirow{2}{*}{$\begin{array}{l}\text { Cell } \\
\text { loss }\end{array}$} & \multirow{2}{*}{$\begin{array}{l}\text { Stromal } \\
\text { loss }\end{array}$} & \multicolumn{2}{|c|}{ Inflammation } & \multirow{2}{*}{$\begin{array}{l}\text { Cell } \\
\text { loss }\end{array}$} & \multirow{2}{*}{$\begin{array}{l}\text { Stromal } \\
\text { loss }\end{array}$} & \multicolumn{2}{|c|}{ Inflammation } \\
\hline & & & & Acute & Chronic & & & Acute & Chronic \\
\hline 1 & ++ & ++ & ++ & ++ & - & ++ & + & + & - \\
\hline 2 & ++ & ++ & + & + & - & ++ & - & - & - \\
\hline 3 & - & ++ & ++ & + & + & ++ & - & - & - \\
\hline 4 & + & ++ & - & + & - & ++ & - & - & - \\
\hline 5 & + & $(++)$ & ++ & + & - & ++ & - & - & - \\
\hline 6 & + & ++ & + & ++ & - & ++ & - & - & - \\
\hline 7 & + & ++ & + & ++ & - & ++ & - & - & - \\
\hline 8 & - & + & - & ++ & - & - & - & - & - \\
\hline 9 & + & ++ & + & ++ & - & - & - & - & + \\
\hline 10 & - & + & + & - & - & + & - & - & - \\
\hline 11 & - & + & - & ++ & - & + & - & - & - \\
\hline 12 & + & ++ & + & ++ & - & + & - & + & - \\
\hline 13 & ++ & ++ & + & ++ & - & ++ & - & - & - \\
\hline 14 & ++ & ++ & - & - & - & ++ & - & - & - \\
\hline 15 & ++ & ++ & + & + & - & + & - & - & - \\
\hline 16 & + & + & + & ++ & - & ++ & - & - & - \\
\hline 17 & - & + & - & ++ & - & - & - & - & - \\
\hline 18 & - & + & ++ & - & - & ++ & - & - & - \\
\hline 19 & - & $(++)$ & ++ & - & - & - & - & ++ & - \\
\hline 20 & ++ & ++ & - & ++ & - & ++ & - & + & - \\
\hline 21 & ++ & ++ & ++ & ++ & - & ++ & - & - & - \\
\hline 22 & ++ & ++ & ++ & ++ & - & ++ & ++ & + & - \\
\hline 23 & ++ & ++ & ++ & ++ & - & ++ & ++ & ++ & - \\
\hline 24 & ++ & ++ & + & ++ & - & + & - & ++ & - \\
\hline 25 & ++ & ++ & ++ & ++ & - & ++ & + & ++ & - \\
\hline 26 & ++ & ++ & + & ++ & - & ++ & - & - & - \\
\hline 27 & ++ & ++ & + & ++ & - & - & - & + & - \\
\hline 28 & ++ & ++ & + & ++ & - & ++ & - & - & - \\
\hline 29 & ++ & ++ & - & ++ & - & ++ & - & + & - \\
\hline 30 & - & ++ & ++ & + & - & ++ & - & - & - \\
\hline
\end{tabular}

$\star$ Bracketed entries represent cases with superimposed reparative fibrosis. ( $++=$ conspicuous finding; $+=$ minor change; $-=$ absent).

Table 2

\begin{tabular}{|c|c|c|c|}
\hline Patient & $\begin{array}{l}\text { Mode of } \\
\text { infection }\end{array}$ & $\begin{array}{l}\text { Recurrence } \\
\text { after } \\
\text { initial graft }\end{array}$ & Other comments \\
\hline $\begin{array}{r}1 \\
2 \\
3 \\
4 \\
5 \\
6 \\
7 \\
8 \\
9 \\
10 \\
11 \\
12 \\
13 \\
14 \\
15 \\
16 \\
17 \\
18 \\
19 \\
20 \\
21 \\
22 \\
23 \\
24 \\
25 \\
26 \\
27 \\
28 \\
29 \\
30\end{array}$ & $\begin{array}{l}\text { Trauma } \\
\text { CL } \\
\text { CL } \\
? \\
\text { CL } \\
? \\
\text { CL } \\
? \\
? \\
? \\
? \\
\text { CL } \\
\text { Trauma } \\
\text { CL } \\
\text { CL } \\
\text { Trauma } \\
\text { CL } \\
\text { CL } \\
\text { CL } \\
? \\
\text { CL } \\
\text { Trauma } \\
\text { Trauma } \\
? \\
\text { CL } \\
? \\
\text { CL } \\
\text { CL } \\
\text { CL } \\
\text { CL }\end{array}$ & $\begin{array}{l}\text { Yes } \\
\text { Yes } \\
\text { No } \\
\text { No } \\
\text { Yes } \\
? \\
? \\
? \\
\text { Yes } \\
\text { Yes } \\
\text { No } \\
\text { Yes } \\
\text { Yes } \\
\text { No } \\
\text { No } \\
\text { No } \\
\text { No } \\
\text { Yes } \\
\text { No } \\
\text { No } \\
\text { Yes } \\
? \\
? \\
\text { No } \\
\text { No } \\
? \\
\text { No } \\
\text { No } \\
\text { Yes } \\
\text { No }\end{array}$ & $\begin{array}{l}\text { Agricultural worker } \\
\text { Retrocorneal membrane } \\
\text { Perforation; evisceration } \\
\text { Perforation; enucleation } \\
\\
\text { Severe uveitis; enucleation } \\
\text { Bilateral involvement } \\
\text { Possible scleral spread } \\
\text { Retrograft fibroplasia } \\
\text { Retrocorneal fibrosis }\end{array}$ \\
\hline
\end{tabular}

Table 3 Summary of histopathological changes in Acanthamoeba infected corneas

\begin{tabular}{lll}
\hline & $\begin{array}{l}\text { Anterior stroma } \\
(30 \text { cases })\end{array}$ & $\begin{array}{l}\text { Posterior stroma } \\
(29 \text { cases })\end{array}$ \\
\hline $\begin{array}{l}\text { Epithelial cell loss: } \\
\text { conspicuous }\end{array}$ & 15 & \\
$\begin{array}{c}\text { slight } \\
\text { Keratocyte loss: }\end{array}$ & 6 & \\
$\begin{array}{c}\text { conspicuous } \\
\text { slight }\end{array}$ & 25 & 21 \\
$\begin{array}{l}\text { Reparative fibrosis } \\
\begin{array}{l}\text { Stromal loss: } \\
\text { conspicuous }\end{array}\end{array}$ & 5 & 4 \\
$\begin{array}{c}\text { slight } \\
\text { Acute inflammation: } \\
\text { conspicuous } \\
\text { slight }\end{array}$ & 10 & 0 \\
\hline
\end{tabular}

affected individuals, ${ }^{78}$ while the recovery rate for Acanthamoeba in nasal and pharyngeal swabs, though low, exceeds the incidence of clinical disease. ${ }^{9-11}$ Subclinical exposure to infection may be the rule rather than the exception. ${ }^{2}$ Such findings, together with the observation that nonocular Acanthamoeba infections, particularly in the form of meningoencephalitis, ${ }^{12} 13$ occur predominantly in immunocompromised patients suggest that the infection is normally easily contained. Immune mechanisms are unlikely, however, to be involved in the apparent inability of the protozoa to infect the cornea in the first instance and it remains to be seen to what extent the low incidence of acanthamoebic keratitis is a reflection of innate protozoal limitations. Conversely, the difficulty experienced by several research workers in artificially infecting animals with Acanthamoeba spp, other than by direct inoculation into the substantia propria, ${ }^{14-17}$ points to the importance of the barrier presented by the epithelium. Experimental evidence indicates that the ability of the parasite to adhere to the surface cells is crucial if infection is to occur and that, while duration of exposure increases the chance, tear flow and eyelid movements act adversely. ${ }^{18}$ Properties peculiar to the corneal surface may also be important, an experimental investigation of corneal infection by Acanthamoeba castellanii having shown that there is marked host specificity, such that whereas the epithelium of humans and pigs permits trophozoite binding, that of most other species does not. ${ }^{19}$ The binding appears to involve a mutual interaction between trophozoites and the surface epithelium such that desmosome-like junctions are created. ${ }^{20}$

In patients with acanthamoebic keratitis preceded by trauma it is reasonable to suppose that the protozoa gained access to the stroma through a physically created gap in the corneal epithelium. The much more common association with contact lens wearing $(78.9 \%$ of the present patients for whom information concerning the possible cause was given) is less obvious for, while minor abrasion of the epithelium is a possibility, there is rarely any clinical evidence of such an event. On the other hand Acanthamoeba spp have been observed lifting up and burrowing between the individual epithelial cells of cocultured corneal tissue.21 Reduced antimicrobial effectiveness of the tear film and bacterial contamination of the prosthesis could also be factors. ${ }^{22}$

In the absence of repeated biopsies concepts of pathogenesis based on the appraisal of histological material can only be inferred but, after initial breaching or invasion of the epithelium, a sequence involving four successive stages can be envisaged (Fig 5).

\section{STAGE 1: INITIAL INFECTION}

Once having reached the substantial propria by whatever means the parasites invade the superficial lamellae without, it seems, exciting any significant inflammatory response. This statement is, however, somewhat conjectural since there is rarely opportunity to observe the initial stages histologically. Even so it is common to see 
Figure 5 Diagram of postulated sequence in the pathogenesis of

acanthamoebic keratitis. $(A)$ Initial penetration of surface epithelium. (B) Depletion of stromal keratocytes by invading Acanthamoebae. (C) Secondary neutrophil polymorphonuclear leucocyte infiltration of stroma. (D) Stromal necrosis.

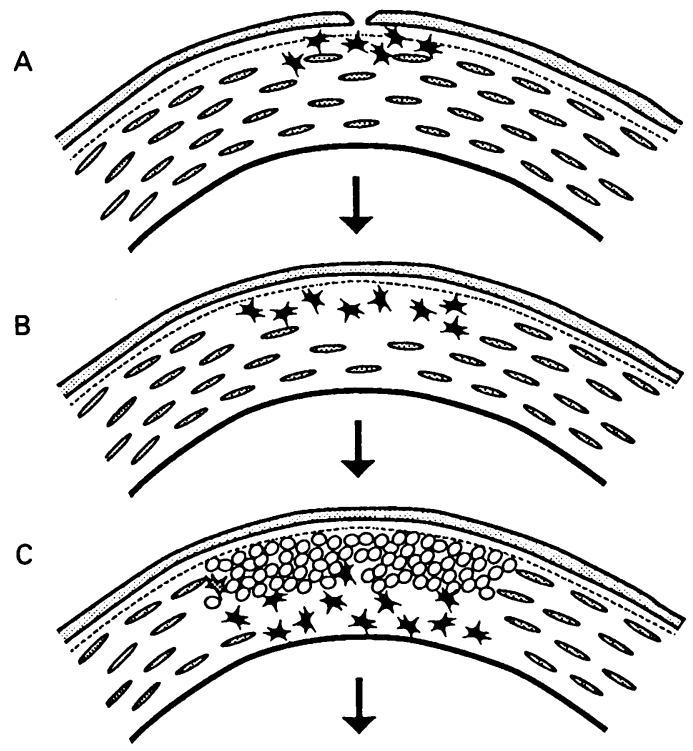

D

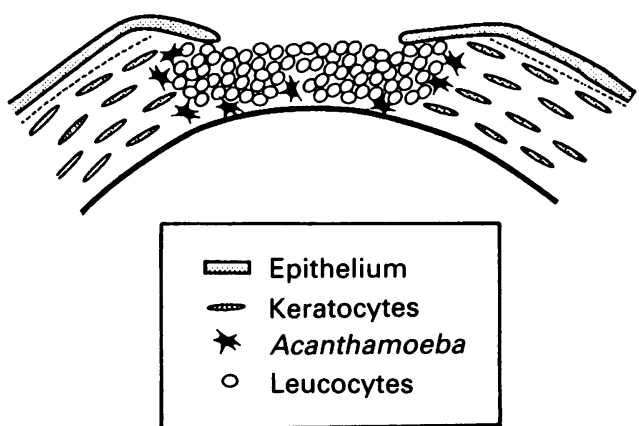

trophozoites and cysts in the deeper stroma in established infections without surrounding leucocytic infiltration. Thus, whereas trophozoites or cysts were identified in the posterior half of the stroma in 28 out of the 30 cases, inflammatory cells were seen in just $\mathbf{1 0}$ and in six of those the numbers were trivial. The relevance of some potentially adverse evidence of an early polymorphonuclear leucocyte response culled from experiments in rats ${ }^{16}$ is thrown into question by the further evidence that the inflammation becomes chronic after 7 days and results in eventual elimination of the parasite: spontaneous resolution does not appear to occur in the human cornea and in none of the 30 cases was there significant chronic inflammatory cell infiltration.

The absence of leucocytes at this phase of the infection invites comparison with certain parasitic disorders of the cornea wherein it is principally dying or degenerate organisms that attract an inflammatory response. Microfilariae of Onchocerca volvulus, for instance, injected into the perilimbal conjunctiva of rabbits under experimental conditions, invade the cornea and persist for several days without attendant leucocytes so long as they remain viable. ${ }^{23}$ It is not clear, however, whether a similar relationship pertains in the case of Acanthamoeba.

\section{STAGE 2: KERATOCYTE DEPLETION}

A reduced keratocyte population appears to be a constant finding, especially in the anterior part of the stroma ( $100 \%$ of cases in the present study), although some attempt at replacement with scar tissue formation may occasionally be seen. The loss of keratocytes appears to be independent of any inflammatory reaction since, whereas the depletion extended through the full thickness of the stroma in 25 cases $(83.3 \%)$, leucocytes were confined to the anterior lamellae in all but 10 (33.3\%). The growth of cultured Acanthamoeba is supported by supplementation with corneal cells but not with essentially extracellular stromal homogenates ${ }^{24}$ and it is feasible that the disappearance of keratocytes is a consequence of their being consumed by the trophozoites, as suggested by the in vitro studies of Larkin and colleagues. ${ }^{25}$

\section{STAGE 3: INFLAMMATORY RESPONSE}

All 30 cases were characterised by identifiable stromal cell loss and in $25(83.3 \%)$ this was associated with an acute inflammatory cell infiltration. In only one instance was leucocytic infiltration seen in the apparent absence of stromal devitalisation, which suggests that the inflammation followed rather than preceded the keratocyte depletion. The stimulus to leucocytic infiltration is open to question but may be a response to the parasite which has been shown to be capable of triggering the alternative pathway of complement activation. ${ }^{26}$ This is perhaps a more likely explanation than its being a consequence of the keratocyte loss since stromal devitalisation occurring in other circumstances, such as failed transplants, is rarely associated with an inflammatory reaction. The composition of the infiltrate was predominantly neutrophil polymorphonuclear cell with some macrophages, but lymphoid cells were conspicuous by their absence. A dearth of lymphocytes and plasma cells has also been noted by others. ${ }^{27}{ }^{28}$ This cannot be construed as a lack of immunogenicity because in those cases in which the whole eye was available for inspection these cells were prominent in both the limbal conjunctiva and anterior uvea. Possibly the absence of lymphoid cells has to do with the observed absence of stromal vascularisation and consequent barrier to invasion by relatively immotile cells. (To what extent the apparent failure of the parasite to infect the sclera, at least to any significant degree, is due to the vascularity and consequent proximity of the effector arm of the immune system remains to be determined). The seeming absence of lymphoid cells is especially intriguing given the abolition of subepithelial infiltrates in patients with acanthamoebic keratitis following topical corticosteroid administration. ${ }^{29}$ The reasonable inference that an Arthus-type immune reaction has occurred in such circumstances could mean that the infiltrates are a consequence of protozoal antigen combining with antibody diffusing from the limbus to form complexes which then initiate the classic pathway of complement activation and a polymorphonuclear leucocyte response.

\section{STAGE 4: STROMAL NECROSIS}

Reduced thickness of the stroma collagen was seen in 23 cases $(85 \cdot 2 \%$ of resected discs and enucleated globes) and in 18 was accompanied by 
an acute inflammatory cell infiltration. This can be taken to infer that the lysis was attributable to enzymes released by the neutrophil polymorphonuclear leucocytes. If so the process is comparable to the neutrophil-mediated collagenolysis described in experimentally induced corneal alkali burns. ${ }^{30}$ It is noteworthy, however, that there were six cases of significant stromal necrosis in either the absence of a recognisable leucocytic response or with minimal inflammatory cell infiltration. This suggests that other or additional factors, such as collagenolytic enzymes secreted by the Acanthamoeba trophozoites, ${ }^{31}$ may be involved. Alternatively, it may be that the apparent discrepancy reflects the effects of antiamoebic drug therapy and the time interval between the active phase of the keratitis and surgery. The extent to which the neutrophils are able to kill Acanthamoeba spp and counterbalance their harmful consequence is uncertain, especially in relation to encysted forms, while in vitro experiments suggest that they need the cooperation of both complement and antibody to be effective. ${ }^{32} 33$

In summary it appears that the following sequence of events could account for the observed histological findings:

(1) Parasitic invasion of the anterior stroma through a defect in the covering epithelium.

(2) Phagocytosis and consequent depletion of keratocytes beginning anteriorly and gradually spreading to involve the full thickness of the cornea.

(3) Secondary acute inflammatory cell infiltration of the devitalised stroma.

(4) Stromal necrosis attributable to leucocytic and parasitic collagenolysis.

It is not the purpose of this paper to discuss the outcome of treatment save to comment that 10 of the 30 patients suffered recurrent keratitis following the initial graft procedure. This suggests that amoebic invasion of the perilimbal zone is not uncommon but, as indicated earlier, the sporadic distribution of organisms renders any attempt to determine whether the margins of resected discs are free of involvement a forlorn exercise. Anterior scleritis is a well documented complication of Acanthamoeba keratitis which could mean that the inflammation reflects direct protozoal infection. Alternatively, detailed study of a case reviewed elsewhere, ${ }^{1}$ led to the conclusion that indirect immunological phenomena were more likely and it may be significant that in none of the five enucleation specimens in the present series was it possible to demonstrate Acanthamoeba. The nature of the stimulus to scleral inflammation and the occasional persistence of scleritis after corneal transplantation in patients with acanthamoebic keratitis clearly needs further investigation.

1 Auran JD, Starr MB, Jakobiec FA. Acanthamoeba keratitis: a review of the literature. Cornea 1987; 6:2-26.

2 Badenoch PR. The pathogenesis of Acanthamoeba keratitis. Aust NZ F Ophthalmol 1991; 19: 9-20.

3 Stehr-Green JK, Bailey TM, Visvesvara GS. The epidemiology of Acanthamoeba keratitis in the United States. $A m \mathcal{F}$ Ophthalmol 1989, 107: 331-6.
4 Ma P, Visvesvara GS, Martinez AJ, Theodore FH, Daggett P-M, Sawyer TK. Naegleria and Acanthamoeba infections: review. Rev Infect Dis 1990; 12: 490-513.

5 He YG, McCulley JP, Alizadeh H, Pidherney M, Mellon J, Ubelaker JE, et al. A pig model of Acanthamoeba keratitis: transmission via contaminated contact lenses. Invest transmission via contaminated co

6 Garner A. Pathology of corneal acanthamoebic infection. In: Cavanagh DH, ed. The cornea: trans wld cong on the cornea Cavanagh DH, ed. The cornea: trans wld cong on the corne

7 Cerva L. Acanthamoeba culbertsoni and Naegleria fowleri: occurrence of antibodies in man. $f$ Hyg Epidemiol Microbiol Immunol 1989; 33: 99-102.

8 Cursons RTM, Brown TJ, Keys EA. Immunity to pathogenic free-living amoebae. Lancet 1977; i: 875-6.

9 Cerva L, Serbus C, Skocil V. Isolation of limax amoebae from the nasal mucosa of man. Fol Parasitol 1973; 20: 97-103.

10 Lawande RV, Abraham SN, John I, Egler LJ. Recovery of soil amebas from the nasal passages of children during the dusty harmattan period in Zaria. Am $\mathcal{F}$ Clin Pathol 1979; 71: 201-3.

11 Badenoch PR, Grimmond TR, Cadwgan. J, Deayton SE, Essery MSL, Hill BD. Nasal carriage of free-living amoebae. Microb Ecol Health Dis 1988; 1: 209-11.

12 Martinez AJ, Janitschke K. Acanthamoeba, an opportunistic microorganism: a review. Infection 1985; 13: 251-6.

13 Gonzalez MM, Gould E, Dickinson G, Martinez AJ Visvesvara G, Cleary TJ, et al. Acquired immunodeficiency syndrome associated with Acanthamoeba infection and other opportunistic infections. Arch Path Lab Med 1986; 110: 749-51.

14 Font RL, Tapert MJ, Robinson NM, Osato MS, Jones DB. An animal model of Acanthamoeba keratitis. Invest Ophthalmol Vis Sci 1981; 20 (ARVO abstracts): 8.

15 Badenoch PR, Johnson AM, Christy PE, Coster DJ. Pathogenicity of Acanthamoeba and a Corynebacterium in the rat genicity of Acanthamoeba and a Corynebacter
cornea. Arch Ophthalmol 1990; 108: 107-12.

16 Larkin DFP, Easty DL. Experimental Acanthamoeba keratitis: I. Preliminary findings. Br $\mathcal{F}$ Ophthalmol 1990; 74: $551-5$.

17 Côté MA, Irvine JA, Rao NA, Trousdale MD. Evaluation of the rabbit as a model of Acanthamoeba keratitis. Rev Infect Dis 1991; 13 (Suppl): S443-4.

18 Osato MS, Pyron M, Elizondo M, Brown E, Wilhelmus K Jones D. Adherence and penetration of human cornea epithelium by Acanthamoeba. Invest Ophthalmol Vis Sci 1990; 31 (Suppl): 420.

19 Niederkorn JY, Ubelaker JE, McCulley JP, Stewart GL, Meyer DR, Mellon JA, et al. Susceptibility of corneas from various animal species to in vitro binding and invasion by Acanthamoeba castellani. Invest Ophthalmol Vis Sci 1992; 33: Acantham 104 .

20 Ubelaker JE, Moore MB, Martin JH, Silveny R, Dougherty JM, Meyer DR, et al. In vitro intercellular adherence of Acanthamoeba castellani: a scanning and transmission electron microscopy study. Cormea 1991; 10: 299-304.

21 Moore MB, Ubelaker JE, Martin JH, Silvany R, Dougherty JM, Meyer DR, et al. In vitro penetration of human cornea epithelium by Acanthamoeba castellani: a transmission and scanning electron microscopy study. Cornea 1991; 10: 291-8.

22 Jones DB. Acanthamoeba - the ultimate opportunist. $A m \mathcal{F}$ Ophthalmol 1986; 102: 527-30.

23 Garner A, Duke BOL, Anderson J. A comparison of the lesions produced in the cornea of the rabbit eye by microlesions produced in the cornea of the rabbit eye by micro-
filariae of the forest and Sudan-savanna strains of Onchocerca filariae of the forest and Sudan-savanna strains of Onchocerca volvulus from Cameroon.

24 Stopak SS, Roat MI, Nauheim RC, Turgeon PW, Sossi G, Kowalski RP, et al. Growth of Acanthamoeba on human corneal epithelial cells and keratocytes in vitro. Inves Ophthalmol Vis Sci 1991; 32; 354-9.

25 Larkin DFP, Berry M, Easty DL. In vitro pathogenicity of Acanthamoeba. Eye 1991; 5: 560-8.

26 Ferrante A, Rowan-Kelly B. Activation of the alternative pathway of complement by Azanthamoeba culbertsoni. Clin Exp Immunol 1983;54: 477-85.

27 Theodore FH, Jakobiec FA, Juechter KB, Ma P, Troutman RC, Pang PM, et al. The diagnostic value of a ring infiltrate in acanthamoebic keratitis. Ophthalmology 1985; 92: 1471-9.

28 Mathers W, Stevens G, Rodrigues M, Chan CC, Gold J, Visvesvara GS, et al. Immunopathology and electron microscopy of Acanthamoeba keratitis. Am $\mathcal{F}$ Ophthalmol 1987 103: 626-35

29 Holland EJ, Alu IH, Meisler DM, Epstein RJ, Rotkis WM, Nathenson AL, et al. Subepithelial infiltrates in Acanthamoeba keratitis. Am $\mathcal{F}$ Ophthalmol 1991; 112: 414-8.

$30 \mathrm{Kao}$ WW-Y, Ebert J, Kao CW-C, Covington H, Cintron C. Development of monoclonal antibodies recognizing collagenase from rabbit PMN: the presence of this enzyme in ulcerating corneas. Curr Eye Res 1986; 5: 801-15.

31 He Y, Niederkorn JY, McCulley JP, Stewart GL, Meyer DR, Silvany $\mathrm{R}$, et al. In vivo and in vitro collagenolytic Acanthamoeba castellanii. Invest Ophthalmol Vis Sci 1990; 31: moeba casth $2235-40$.

32 Ferrante A, Abell TJ. Conditioned medium from stimulated mononuclear leukocytes augments human neutrophilmediated killing of a virulent Acanthamoeba $s p$. Infect Immunol 1986; 51: 607-17.

33 Ferrante A. Immunity to Acanthamoeba. Rev Infect Dis 1991; 13 (Suppl): S403-9. 